\title{
Sodium-23 NMR Studies of Sodium Ion Ensembles with a 1,3-Alternate-Shaped Calix[4]arene
}

\author{
Takashi Arimura $^{1 *}$, Takuya Nishioka ${ }^{1}$, Satoshi Kumamoto $^{1}$, Youichi Tsuchiya $^{1}$, \\ Tomohiko YAMAguCHI $^{1}$ and M. TACHIYA ${ }^{2}$ \\ ${ }^{I}$ Nanotechnology Research Institute, National Institute of Advanced Industrial Science and Technology (AIST) \\ (Tsukuba Central 5, Tsukuba 305-8565, JAPAN) \\ ${ }^{2}$ Fellow, National Institute of Advanced Industrial Science and Technology (AIST) \\ (Tsukuba Central 5, Tsukuba 305-8565, JAPAN)
}

Edited by J. Sekiya, Kyoto Univ., and accepted October 17, 2005 (received for review September 22, 2005)

\begin{abstract}
Sodium-23 NMR longitudinal magnetization recovery (L.M.R.) study has been carried out to clarify the sodium ion exchange in ensembles with 1,3-alternate-shaped calix[4]arene 1 for the first time. The line width $v_{1 / 2}$ of a sharp singlet for $\mathrm{NaClO}_{4}$ in the absence of 1 is $65 \mathrm{~Hz}$ : upon addition of 1 a singlet peak was broadened to $1100 \mathrm{~Hz}\left(v_{1 / 2}\right)$. The life times $(\tau)$ of $\mathrm{Na}^{+}$were estimated to be $(20-3.8) \times 10^{-3} \mathrm{~s}$ for $\tau_{\mathrm{A}}$ and $(5.0-2.0) \times 10^{-3} \mathrm{~s}$ for $\tau_{\mathrm{B}}$, by the simulations of sodium-23 NMR L.M.R. curves. The life times of 1-Na ${ }^{+}$Ensemble are larger than those for 18 -crown- 6 . This implies that $\mathrm{Na}^{+}$cation is bound deeply in the cavity formed by two $\mathrm{OCH}_{2} \mathrm{CO}$ groups of $\mathbf{1}$, the complex being classified as a "nest-in-type".

Key words: sodium-23 NMR, longitudinal magnetization recovery, life time, 1,3alternate-shaped calix[4]arene, sodium ion, spin-lattice relaxation, molecular tweezer, molecular recognition
\end{abstract}

\section{Introduction}

The complexation of alkali-metal ions by supramolecules is a subject of substantial current interest, because organoalkali substrates are of fundamental importance both in modern organic synthesis (1-3) and in molecular devices (4). Calixarene has been receiving increasing attention in the field of supramolecular chemistry (5). It has been found that the ester derivatives show the ionophoric nature and are capable of binding alkali metal, alkaline earth metal, diazonium ions as crown ethers do (6-10). In particular, the 1,3alternate-shaped calix[4]arene possessing two ester groups $\mathbf{1}$ exhibits moderate selectivity towards $\mathrm{Na}^{+}$ (11). This is attributable to the internal size of the ionophoric cavity made up by the two $\mathrm{OCH}_{2} \mathrm{C}=\mathrm{O}$ groups, which is comparable with the ion size of $\mathrm{Na}^{+}$
(12). In order to understand the selectivity for the metals, it is of great significance to access the kinetic properties of sodium ion ensembles with 1,3-alternateshaped calix[4]arene (Fig. 1). Among NMR spectroscopic methods, it is known that sodium-23 NMR longitudinal magnetization recovery (L.M.R.) studies could provide further insights into the binding dynamics of included sodium ion (13). Herein, we describe systematic studies through ${ }^{23} \mathrm{Na}$ NMR L.M.R. of an ionophoric 1,3-alternate-shaped calix[4]arene ester $\mathbf{1}$. The main purpose of this work is to clarify the sodium ion exchange between encapsulated sodium ion and solvated sodium ion.

\footnotetext{
*Correspondence to: Takashi ARIMURA, National Institute of Advanced Industrial Science and Technology (AIST), Tsukuba Central 5, Tsukuba 305-8565, JAPAN

E-mail: takashi-arimura@aist.go.jp
} 


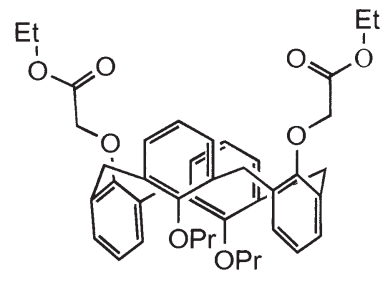

1

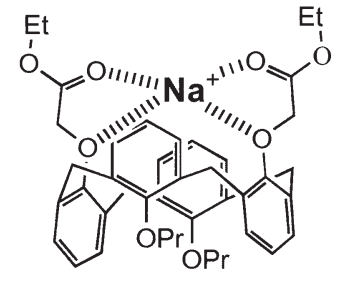

1-Na ${ }^{+}$Ensemble
Fig. 1 Substrates 1 and $\mathbf{1 - N a}{ }^{+}$Ensemble.

\section{Experimental}

\subsection{Materials}

2-(Ethoxycarbonylmethoxy)xylene $\mathbf{2}$ was used as a reference compound. The synthesis of 1,3-alternateshaped 25,27-dipropoxy-26,28-bis(ethoxycarbonylmethoxy)- calix[4]arene $\mathbf{1}$ was described previously (14).

\section{$\mathbf{2} \cdot \mathbf{2}$ NMR Measurements}

NMR samples consisted of $0.5 \mathrm{ml}$ of solution in 5$\mathrm{mm}$ o.d. tubes which were sealed under vacuum after degassing by 5 freeze-pump-thaw cycles. All glasswares were washed with $0.01 \mathrm{M}$ ethylenediaminetetraacetic acid (EDTA) solution to remove paramagnetic impurities. Perdeuteriotetrahydrofuran $\left(\mathrm{THF}-\mathrm{d}_{8}\right)$ and perdeuteriomethanol $\left(\mathrm{CD}_{3} \mathrm{OD}\right)$ were used as a solvent. ${ }^{23} \mathrm{Na}$ NMR spectra were recorded on a Varian Gemini300 spectrometer operated at $300 \mathrm{MHz}$ in the Fourier transform mode to study the spectroscopic behaviors of sodium perchlorate $\left(\mathrm{NaClO}_{4}\right)$ in the absence and the presence of $\mathbf{1}$. The L.M.R. curves were estimated from the time $(\tau)$ evolution of the heights of spectra taken by inversion recovery method (15). As shown in Fig. 2, when the resonance frequencies of ${ }^{23} \mathrm{Na}$ nuclei in two environments are almost the same magnitude, the total longitudinal magnetization is proportional to the heights of spectra.

\section{Results and Discussion}

As shown in Fig. 2, we found that the addition of the calixarene derivatives 1 made the ${ }^{23} \mathrm{Na}$ NMR spectra very broad at $25^{\circ} \mathrm{C}$. So, the line width $v_{1 / 2}$ of a sharp singlet for $\mathrm{NaClO}_{4}$ in the absence of $\mathbf{1}$ is $65 \mathrm{~Hz}$ : upon addition of 1 a singlet peak was broadened to $1100 \mathrm{~Hz}$ $\left(v_{1 / 2}\right)$. The line shapes of the spectra in the absence and the presence of 1 were single Lorentzians at $25^{\circ} \mathrm{C}$. Further examination of the ${ }^{23} \mathrm{Na}$ NMR spectra, the L.M.R. curves between $0{ }^{\circ} \mathrm{C}$ and $60^{\circ} \mathrm{C}$ showed single exponential decays. This suggests that, in 1,3-alternate-shaped calix[4] arene ester $\mathbf{1}$, the $\mathrm{CH}_{2} \mathrm{CO}_{2}$ Et groups suppress the motion of $\mathrm{Na}^{+}$. In contrast, the ${ }^{23} \mathrm{Na} \mathrm{NMR}$ spectrum of $\mathrm{NaClO}_{4}$ was not affected at all by the addition of the reference compound 2 (even at $8.0 \times 10^{-2} \mathrm{M}$ ). This means that $\mathbf{2}$ does not form the complex with $\mathrm{Na}^{+}$.

The calixarene derivative 1 shows a doublet (3.80, $3.90 \mathrm{ppm}$ ) for the $\mathrm{ArCH}_{2} \mathrm{Ar}$ protons and this split pattern was not affected by the measurement temperature $\left(0-60^{\circ} \mathrm{C}\right)$. This indicates that $\mathbf{1}$ adopts a 1,3-alternate conformation (5) and the oxygen-through-the annulus rotation is inhibited by the $\mathrm{CH}_{2} \mathrm{CO}_{2} \mathrm{Et}$ groups (16). It is reported that $\mathbf{1}$ can bind $\mathrm{Na}^{+}$through interactions with two oxygens in the $\mathrm{OCH}_{2} \mathrm{CO}$ moiety and the association constant $\left(K_{a}\right)$ is $\log K_{a}=3.5$ (11). Hence, we consider that 1 exists totally as a $\mathrm{Na}^{+}$ensemble under the measurement conditions. The large association constant observed for $\mathbf{1}$ is rationalized as for the fitness between the ionophoric cavity formed by two ester groups and the ionic size of $\mathrm{Na}^{+}$. These ${ }^{1} \mathrm{H}$ NMR data are in line with the ${ }^{23} \mathrm{Na}$ NMR spectral data discussed above. 
Thus, the temperature dependence of ${ }^{23} \mathrm{Na}$ NMR can be attributed to the chemical exchange reaction between two sites A and B (Equation 1).

The spin-lattice relaxation rates $R_{A}$ and $R_{B}$ between $0^{\circ} \mathrm{C}$ and $60^{\circ} \mathrm{C}$ attained from the slopes of the L.M.R. curves were equal to $5300 \sim 1700 \mathrm{~S}^{-1}$ and $130 \sim 60 \mathrm{~S}^{-1}$, respectively. This indicates that the interaction of the nuclear quadrupole moment with electric field gradients becomes very large between a sodium nucleus and oxygen atoms of the $\mathrm{OCH}_{2} \mathrm{CO}$ groups in 1- $\mathbf{N a}^{+}$Ensemble. We can calculate the life times of $\mathrm{Na}^{+}$with the simulations of the L.M.R. curves and also the evolution of the longitudinal magnetization $\mathrm{M}_{\mathrm{Z}}(\tau)$ is estimated as a following equation 2 (15): where $R_{A}$ and $R_{B}$ are given by the spin-lattice relaxation rate, the life times, and the fractional population. The life times $(\tau)$ of $\mathrm{Na}^{+}$were estimated to be $(20 \sim 3.8) \times 10^{-3} \mathrm{~s}$ for $\tau_{\mathrm{A}}$ and $(5.0 \sim 2.0)$ $\times 10^{-3} \mathrm{~s}$ for $\tau_{\mathrm{B}}$, respectively. As shown in Fig. 3, the life times of $\mathrm{Na}^{+}$were efficiently enhanced in the presence of 1 . In particular, the life time $\left(\tau_{\mathrm{A}}: 2.0 \times 10^{-2} \mathrm{~s}\right.$ at $\left.25^{\circ} \mathrm{C}\right)$ of $\mathbf{1 - \mathbf { N a } ^ { + }}$ Ensemble is larger than those $\left(\tau_{\mathrm{A}}\right.$ between $10^{-4} \sim 10^{-6} \mathrm{~s}$ at $23^{\circ} \mathrm{C}$ ) for 18 -crown-6 (13). This implies that $\mathrm{Na}^{+}$cation is bound deeply in the cavity formed by two $\mathrm{OCH}_{2} \mathrm{CO}$ groups of $\mathbf{1}$, the complex being classified as a "nest-in-type". As the cavity size of 18-crown- 6 is greater than the size of $\mathrm{Na}^{+}$cation, the complex is not so stable. That is, the greater $\tau_{\mathrm{A}}$, the larger association constant obtains.

The foregoing results demonstrate that, in 1,3-alternate-shaped calix[4] arene 1 , the motion of $\mathrm{Na}^{+}$cation is

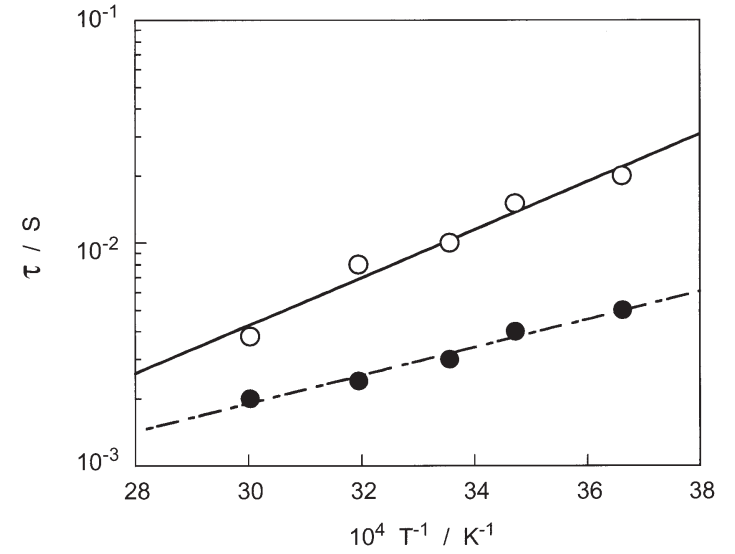

Fig. 3 Plots of ${ }^{23} \mathrm{Na}$ NMR Life Times $\tau_{\mathrm{A}}(\bigcirc$ in the Presence of $\mathbf{1})$ and $\tau_{\mathrm{B}}(\mathbf{i n}$ the Absence of $\mathbf{1})$ versus Temperature. $\left[\mathrm{Na}^{+}\right]=8.0 \times 10^{-3} \mathrm{M}$, $[\mathbf{1}]=2.0 \times 10^{-2} \mathrm{M}, \mathrm{CDCl}_{3}-\mathrm{THF}-\mathrm{d}_{8}(3: 1 \mathrm{v} / \mathrm{v})$.

completely suppressed and two $\mathrm{OCH}_{2} \mathrm{CO}$ groups of $\mathbf{1}$ play an important role to freeze the fluctuational motion of $\mathrm{Na}^{+}$cation.

In conclusion, the present paper shows the first study on ${ }^{23} \mathrm{Na}$ NMR life times of $\mathrm{Na}^{+}$cation included in 1,3alternate-shaped calix[4]arene. It is clear that the calixarene skeleton efficiently suppresses the molecular motion of $\mathrm{Na}^{+}$cation through complexation. Further examination on the conformational motions in 1,3-alternate-shaped calix[4]arene possessing two ester groups as molecular machine is now under investigation.

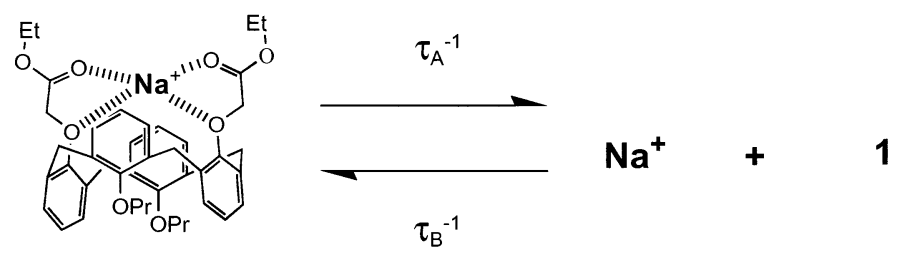

1-Na ${ }^{+}$Ensemble

Solvated $\mathrm{Na}^{+}$

A

B

Equation 1

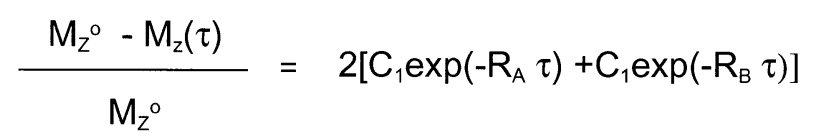

Equation 2 


\section{References}

1. R. UNGARO and E. DALCANDE, Supramolecular Science: Where It Is and Where IT IS Going ?, Kluwer, Dordrecht (1999).

2. M. SHIBASAKI and Y. YAMAMOTO, Multimetallic Catalysts in Organic Synthesis, Wiley-VCH, Wheinheim (2004).

3. I. HAIDUC and F.T. EDELMANN, Supramolecular Organometallic Chemistry, Wiley-VCH, Wheinheim (1999).

4. V. BALZANI, A. CREDI and M. VENTURI, Molecular Devices and Machines, Wiley-VCH, Weinheim (2003).

5. J. VICENS and V. BOHMER, Calixarenes, a Versatile Class of Macrocyclic Compounds, Kluwer, Dordrecht (1991).

6. S. SHINKAI, S. EDAMITSU, T. ARIMURA and O. MANABE, Can Calixarene Esters Stabilize Arenediazonium Ions by Complexation?, J. Chem. Soc., Chem. Commun., 1622-1623 (1988).

7. T. ARIMURA, M. KUBOTA, T. MATSUDA, O. MANABE and S. SHINKAI, Formation of Solvent-Separated Ion Pairs in Calixarene Ester-Alkali Picrate Complexes, Bull. Chem. Soc. Jpn., Vol. 62, 1674-1676 (1989).

8. Y. ISHIKAWA, T. KUNITAKE, T. MATSUDA, T. OTSUKA and S. SHINKAI, Formation of Calixarene Monolayers which Selectively Respond to Metal Ions, J. Chem. Soc., Chem. Commun., 736-738 (1989).

9. T. ARIMURA, T. NISHIOKA, S. IDE, S. KUMAMOTO, S. MURATA and M. TACHIYA, Molecular Complexation of Arenediazonium Ions by a Calix[4]arene Possessing Two Ester Groups: Molecular Tweezers, J. Oleo Sci., Vol. 53, 313-317
(2004).

10. T. ARIMURA, T. NISHIOKA, S. IDE, S. KUMAMOTO, T. YAMAMOTO, T. YAMAGUCHI and M. TACHIYA, Ion Extraction of Alkali Metal Cations by Molecular by a Calix[4]arene Bearing Two Ester Groups, J. Oleo Sci., Vol. 53, 571-573 (2004).

11. T. ARIMURA, T. NISHIOKA, S. IDE, S. MURATA and M. TACHIYA, Formation of Solvent-Separated Ion Pairs in Calix[4]arene Possessing Two Ester Groups: Molecular Tweezers, J. Oleo Sci., Vol. 52, 627-629 (2003).

12. C.D. GUTSCHE, Calixarenes, Royal Society of Chemistry, Cambridge (1989).

13. S.F. LINCOLN, A. WHITE and A.M. HOUNSLOW, Sodium Ion Exchange on the 1,4,7,10,13,16-Hexaoxaoctadecanesodium(I) Cation in Several Solvents, J. Chem. Soc., Faraday Trans. 1, Vol. 83, 2459-2466 (1987).

14. S. IDE, T. ARIMURA, T. NISHIOKA and S. MURATA, Synthesis and Formyl Nitrocalix[4]arenes Each Having Two Ester Groups, J. Oleo Sci., Vol. 50, 927-930 (2001).

15. T. JIN and K. ICHIKAWA, An Aluminium-27 Nuclear Magnetic Resonance Study of Ligand Exchange, J. Chem. Soc., Faraday Trans. 1, Vol. 84, 3015-3025 (1988).

16. T. ARIMURA, S. SHINKAI, T. MATSUDA, Y. HIRATA, H. SATOH and O. MANABE, Fries Rearrangement in Calixarene Esters: A New Entry for the Synthesis of $p$-Substituted Calixarenes, Bull. Chem. Soc. Jpn., Vol. 61, 3733-3734 (1988). 